\title{
Must we choose between quality and cost containment?
}

\author{
Caryl E Carpenter, A Douglas Bender, David B Nash, John M Cornman
}

Health and Medical Services

Administration, Widener University Caryl E Carpenter, associate professor

School of Management, Widener University, 1 University Place, Chester, PA 19013, USA

A Douglas Bender, associate professor

Thomas Jefferson University Hospital, Philadelphia, PA, USA David B Nash, director of health policy and clinical outcomes

\section{Consultants on} Purpose, Arlington, VA,USA

John M Cornman, consultant

Correspondence to: $\operatorname{Dr} C \mathrm{E}$ Carpenter, Health and Medical Services

Administration, Widener University, 1 University Place, Chester, PA 19013 , USA

Accepted for publication 10 September 1996

\section{Introduction}

For the past few years, the United States has been engaged in a public policy debate about how to reform the healthcare system to assure access to care while cost containment. Underlying the deliberations is a concern that quality and cost containment are a trade off - that is, that efforts to contain costs inevitably result in lower quality of care. This concern may explain, in part, why the effort to pass reform legislation two years ago was not successful.

However, quality health care was neither defined nor debated; the concepts and goals of cost containment were neither explored nor explained; and the relation between the two was never discussed. Therefore, the possibility that there is no direct relation or even an inverse relation between quality and cost containment was never raised. Without any public consensus about what is meant by either quality or cost containment, it is difficult to evaluate their relation to each other fairly.

The relation between cost containment and quality is an issue of universal interest. In this paper, we present the issue in the United States and discuss why the concepts of quality and cost containment may be poorly understood. We evaluate how the managed care phenomenon affects public perceptions of the relation between quality and cost containment. And we propose a framework for discussions on future reforms that are based on our understanding and definitions of quality, cost, and cost containment. We think a better framework for discussion is necessary to reach a national consensus on reform of health care.

\section{Background}

In the United States, healthcare expenditures are rising faster than the rest of the economy despite various efforts to contain them. ${ }^{1}$ Consequently, the share of gross national product (GNP) spent on health care is growing; the share in the United States is the highest in the world. ${ }^{2}$ Unlike many western nations, the United States has made fairly limited use of controls on system capacity or prices. The unique United States contribution to cost containment is its focus on control through financial incentives and the micromanagement of medical practice. ${ }^{3}$ The United
States recently ended a long and unsuccessful debate about healthcare reform. That debate was characterised by a lack of consensus on an appropriate strategy for cost containment.

Initially support for President Clinton's plan was high. ${ }^{4}$ Most Americans favoured a plan that would assure universal access and contain costs. Quality of care was not part of the debate. $^{5}$ However, public support eroded quickly, showing significant differences of opinion about the goals of reform and the means to achieve them. ${ }^{6}$ Observers of the United States reform debate have suggested many reasons for its failure. Factors cited include ineffective leadership, the impact of powerful interest groups, public resistance to various financing alternatives, and a congenital American distrust of government. ${ }^{78}$

Yankelovich $^{4}$ attributes the failure to a discrepancy between the views of health experts who crafted the Clinton proposal and the views of the general public. He argues persuasively that the public was not then and is not now adequately informed to participate in a dialogue about reform or to accept any attendant changes. We agree with him. The American public is not well informed, but they are not alone. A better understanding of what is meant by cost containment and quality on the part of consumers, providers, and policy makers alike is a necessary antecedent to reform. Otherwise the health reform debate can be easily sidetracked by the diversionary debates raised by special interest groups who oppose change, as was the case with the Clinton proposal.

Consumers,providers, and policy
makers need to understand the
meaning of quality and cost
containment.

Understanding cost containment DEFINING COSTS

As politicians and pundits talk about the problem of rising costs, it has not been clear what costs they are talking about. When they say they want to control costs do they mean unit costs - what most people would call prices? 
Or do they mean some aggregate measure of cost that is a function of both price and quantity - measures such as lifetime per capita costs, corporate health benefit costs, total national expenditures, or share of GNP? And whose costs do they mean? Are costs to consumers, employers, government, or taxpayers?

Are costs those of consumers,
employers, government, or
taxpayers?

Part of the problem in the United States is that words like costs, prices, charges, and expenditures are used interchangeably when, in fact, their intended meanings are quite different. Costs represent the resources used to produce goods or services. Costs are not the same thing as charges. It may cost a hospital $\$ 1000$ to produce a day of care in a routine medical or surgical inpatient unit, but the hospital may charge $\$ 1500$. It is charges that typically get the bad press, for example the $\$ 10$ charge for one aspirin. When consumers say healthcare costs are too high, they are usually referring to charges. What the typical consumer does not understand is that charges for health services in the United States do not have a consistent relation to costs. Charges are set to recover costs, losses from underpayments of costs, or uncompensated care, plus some margin of profit. ${ }^{9}$

Charges are the same thing as prices. Providers typically substitute the word charge for price. Retailers, such as pharmacies, will use the word price. The difference is that pricing in a retail environment is more straightforward because most retail pricing is on a cost plus margin basis.

The complicated pattern of cross subsidisation that United States hospitals use to set charges is not characteristic of the pricing practices of most retailers.

A healthcare provider's charges are not the same thing as payments. In fact, most third party payers in the United States today do not pay charges. They may pay according to a negotiated fee or they may pay a percentage of charges, but they rarely pay the $\$ 10$ charge for an aspirin. Expenditures are synonymous with payments. For example, the Federal government's expenditures for Medicare are the payments made to providers and these do not necessarily reflect the providers' costs or charges.

For this discussion, we will use the word costs to mean the resources required to produce goods or services. Unit costs refer to the resources required to produce one unit of goods or services - for example, a patient day, an office visit. Total costs involve unit costs and quantity. Expenditures will denote what is paid for goods or services, whether the payer is a consumer, an insurance company, an employer, or government.

Being clear about the meaning of costs and expenditures is very important to our understanding of cost containment. Most of the time people mean containing expenditures when they talk about cost containment - that is, reducing what is paid for health care. Cost control for consumers may mean controlling expenditures per capita, particularly those paid out of pocket. Policy makers may focus on total expenditures, particularly those paid for by the public sector. Rarely does cost containment mean reducing the actual cost of producing health services.

Rarely does cost containment
mean reducing the actual cost of
producing health services.

Understanding what is meant by costs and expenditures is especially important to the concept of managed care as a strategy for containment of costs or expenditures. Are expenditures per capita in managed care plans less than in fee for service plans because of controls on the costs of production, their payments to providers, the use of services, or some combination of the three? The answer to this question determines whether consumers or providers are the primary savers in health maintenance organisations and other managed care plans. And who are the beneficiaries of any savings in managed care? Members, employers, investors, managed care executives, or government?

\section{DEFINING COST SAVINGS}

Being clear about what costs and expenditures mean affects any assessment of cost saving technology. Some technologies may reduce unit costs but not total expenditures. Take the example of laparoscopic cholecystectomy. This procedure is a less expensive alternative to traditional surgical removal of the gall bladder. However, researchers at United States Healthcare (a managed care company) recently documented that provider response to this new technology was to increase the number of cholecystectomies, so the lower unit cost was offset by higher volume. The cost saving technology ultimately increased total expenditures for treatment of gall bladder disease. ${ }^{10}$

However, the study did not include lost productivity in the analysis. That is another potentially relevant cost that might be considered when cost savings are evaluated. If patients who receive the laparoscopic procedure return to work sooner than those who receive the traditional surgical procedure, then the total cost of the episode might be considered lower. In this case, the new procedure may reduce the employer's expenditures for personnel but not for healthcare benefits.

TIME FRAME

The time frame for talking about costs and expenditures is also unclear. United States businesses are often criticised for focusing on short term rather than long term gains. This seems to fit the American penchant for immediate forms of gratification. The same could be said of health policy in the United States. 
Policy makers seem to be searching for the quick solution that will reduce expenditures in the short term rather than investing in services that might reduce expenditures in the long run.

The time frame is important because some strategies to contain expenditures may take time to pay off. Sometimes increasing use now can increase savings later. Preventive care is a good example. A substantial portion of the burden of illness is preventable. So investments in at least some preventive services should reduce aggregate health expenditures in the long term by reducing the need for medical care. ${ }^{11}$ However, some United States insurance companies have been reluctant to finance a broad range of preventive services. The savings may occur in the long term but subscribers do not have a long term commitment to remain enrolled with a particular plan. Thus, the savings may not accrue to the plan that made the investment, an interesting consequence of a multipayer system.

POLICY MAKERS' DEFINITIONS

What do policy makers mean by cost containment? Does containment mean reducing expenditures for health care or simply slowing the rate of growth? Does it mean all expenditures or only public expenditures? Few health policy experts would argue that national health expenditures can be reduced, at least in the short term; most focus on the rate of growth.

During the 1992 presidential election, both Clinton and Bush proposed keeping the increase in expenditures to the inflation rate in the rest of the economy plus population growth. This implied that unit costs would grow no faster than general inflation and use would grow no more than the population. About half the increase in national health expenditures from one year to the next can be attributed to general inflation and population growth; the rest can be attributed to growth in use per capita. ${ }^{12}$ So Clinton and Bush were proposing to contain the number and types of services used per person per year.

Even after controlling for population growth, use rose in the United States due to several factors: advances in medical practice and technology, expansion of insurance coverage, aging of the population, changes in disease patterns, and a growing list of social problems that arrive on the healthcare system's doorstep. ${ }^{13}$ Is it realistic to rein in all of these factors, including the greying of America?! Of course not. Some of these factors are beyond the healthcare system's control; others cannot be put right through health policy alone. Correcting other factors might require sacrifices the public are not willing to make, which brings us to the issue of quality.

\section{Understanding quality}

DEFINING THE BEST

In the United States the concept of quality is affected, first and foremost, by the belief that the United States has the best healthcare system in the world. In the early 1990s, public opinion polls showed that most Americans thought that their healthcare system needed a major overhaul, and yet most also reported high levels of satisfaction with their care. ${ }^{4}$ Despite the perceived need for change, most Americans think that their system is the best. ${ }^{14}$

But what does best mean? The United States trails behind many other developed countries in most measures of health. ${ }^{15}$ Is this the best? It trails most other developed countries in access to health insurance coverage. ${ }^{16}$ Is this the best? In what ways does the American system excel? It does have a higher proportion of physicians who are specialists than any other country and wider availability of complex and very expensive technology. ${ }^{3}$ Is this the best?

Access to highly specialised services and the technology that goes with them is probably what most Americans mean by the best. This may also be what many fear might be lost under reform (thanks in part to misrepresentation of the healthcare systems in other countries by many practitioners, politicians, and the media). Americans have a fascination with technology and an unrealistic faith in its contribution to health. That belief is reinforced by frequent reports of medical breakthroughs and miracle cures.

What is meant by the best is important. If it means technological superiority, that implies Americans think of quality in terms of outputs of the system rather than outcomes of care. An output would be, for example, a radiology procedure; an outcome would be an improvement in ambulation. A focus on outputs means Americans focus on health care, not health.

\section{Advances in medicine foster an expectation that the system can solve almost any problem.}

Faith in the medical care system's outputs also makes it easier for consumers to avoid any personal responsibility for their health. Advances in medicine foster an expectation that the system can solve almost any problem. Many people do not acknowledge that major improvements in health require changes in personal behaviour. If quality is defined in terms of outputs or services, then only the healthcare system can provide quality. If quality is defined in terms of outcomes, then consumers, providers, and policy makers share responsibility for quality.

For many Americans, access is a proxy for quality. They focus on availability of services and the requisite equipment. Services are available, by United States standards, if they are geographically nearby, require little or no wait to use, and can be directly accessed by the consumer. Any proposal to restrict availability by controlling supply or use is viewed as a proposal to lower quality.

CLINICAL DECISION MAKING

To understand quality, one must understand the nature of clinical decision making and the basis for most medical practice. Most Americans do not appreciate the inherent 
uncertainty of many clinical decisions. ${ }^{17}$ Few people understand how little is known about the efficacy of many routine clinical processes or how much of medical practice is justified by the experience of physicians rather than objective evidence.

\section{Few people understand how little is known about the efficacy of many routine clinical processes.}

\begin{abstract}
"Reliance on personal experiences as the basis of existing medical practices has been increasingly questioned. Evidence has been slowly accumulating that suggests that even well-accepted and very common technologies, such as routine chest $x$-rays, can be ineffective, that a substantial number of medical and surgical procedures are performed for inappropriate reasons, that different regions supply very different amounts of medical care with very different costs, despite apparently similar levels of underlying need."18
\end{abstract}

Because consumers do not understand the nature of clinical decisions, they often have unrealistic expectations of medicine and a low tolerance for error.

This implies that the general public do not view quality as an issue of effectiveness or appropriateness. When the public talk about waste in the system, for example, they usually mean that the United States system suffers from many instances of fraud or inefficiency. They do not think that waste means inappropriate or ineffective care, and they typically do not think of quality in those terms either. This makes it difficult for the public to accept that reducing inappropriate care - that is, doing - less could result in better quality.

The public's perception of quality typically does not include dimensions of quality of life. American society is reluctant to limit any treatments that sustain life regardless of its quality. In the United States, for example, expenditures for care in the last year of life are very high and often are the result of overly aggressive and futile treatment. ${ }^{11}$ If Americans find it hard to eschew heroic measures in these circumstances, then they are surely a long way from accepting that doing less might mean a better quality of life.

\section{Understanding the relation between cost containment and quality}

If both quality and cost containment are poorly understood, then it is difficult to evaluate the relation between them. Many Americans subscribe to a general maxim - you get what you pay for. The implication, of course, is that quality and costs are directly related. Higher costs or expenditures imply better quality. Thus, cost containment inevitably jeopardises quality. There are many good examples of circumstances in which spending more money does not result in better quality. The most obvious healthcare example is the low health status of Americans despite having the most expensive healthcare system in the world. ${ }^{15}$ There are many examples outside health care as well.

Practitioners of total quality management argue that quality and cost are not always directly related. Application of the principles of total quality management to American business has provided many examples. ${ }^{19}$ The basic tenets of total quality management are that poor quality is expensive and improvements in quality can reduce costs. ${ }^{20}$ In this case, cost does mean the cost of production. This view of quality and its focus on process are very appropriate for the healthcare industry as well.

\section{Poor quality is expensive and improvements in quality can reduce costs.}

In fact, the principles of total quality management and continuous quality improvement have been enthusiastically embraced by some segments of the healthcare industry, although the public may not be aware of it. Applications of total quality management and continuous quality improvement to health care also have produced encouraging results that show an inverse relation between quality and cost in some instances. It is not clear whether the healthcare industry as a whole or the general public would accept this alternative view of the relation between quality and cost.

\section{RESEARCH ON OUTCOMES}

Several clinicians in the United States have argued that a new paradigm is needed for clinical practice based on a better understanding of the relation between process and outcomes. ${ }^{21-23}$ Wennberg ${ }^{24}$ has been one of the most ardent champions for better evidence of effective medical practices. His work has helped establish the legitimacy of research on outcomes which has also shown an inverse relation between quality and cost under some conditions. Fleming et $a l^{25}$ showed that watchful waiting, the low cost strategy for benign prostatic hypertrophy, often produced better results than more expensive, invasive alternatives. A study of giving antibiotics to surgical patients at Intermountain Health Care in Salt Lake City resulted in a new protocol that significantly reduced postoperative deep wound infections, thus saving money and improving quality. ${ }^{26}$ Researchers in Canada and New York found that regionalisation of cardiac surgery services resulted in better outcomes and lower costs. ${ }^{27}$ Results from a study of nursing homes in Pennsylvania support the argument that cost efficiency can be improved without sacrificing quality. ${ }^{28}$ These are just a few examples of work in the healthcare industry that challenge the belief that you get what you pay for.

Berwick $^{29}$ has suggested several "worthy aims" for reform that could improve the quality of care and reduce costs and expenditures. 
These include reducing inappropriate services, simplifying formularies, expanding the use of information technology, and eliminating underused inpatient services. Schoenbaum ${ }^{5}$ has argued that trends are already emerging in the United States system that offer promise of better quality at a lower cost. These include the integration of systems of care, the development of research on outcomes and clinical guidelines, and the refinement of data on comparative performance.

\section{MANAGED CARE EXPERIENCE}

The managed care phenomenon in the United States health system has had a significant impact on the public's perception of the relation between quality and cost. The experience of the first prepaid group practices was that savings could be achieved without sacrificing quality. These organisations served as the prototypes for health maintenance organisations. An extensive body of research showed that per capita expenditures were $10 \%$ to $40 \%$ lower in the first health maintenance organisations than in fee for service practice, even when controlling for selection bias in choice of plans. ${ }^{30}$ Comparisons between health maintenance organisations and fee for service plans in terms of quality often showed care to be better in health maintenance organisations, particularly in group or staff model plans. ${ }^{30}$

Initial savings in health maintenance organisations came from identifying and reducing the considerable slack in the American healthcare system, primarily through shifting care from inpatient to outpatient settings. ${ }^{30}$ However, there is no evidence that health maintenance organisations are better able to control expenditures in the long term than fee for service insurers. Expenditures of health maintenance organisations per capita are lower than fee for service, but they rise at about the same rate due largely to the updating of technology faced by all financing mechanisms. ${ }^{1331}$ Managed care organisations are under the same pressure to finance new technologies and procedures, regardless of their effectiveness, as their rapidly disappearing fee for service counterparts.

Today health maintenance organisations are just one of various organisational forms called managed care. The more recent managed care experience has created public fear that controls on use are starting to jeopardise quality. Managed care firms have been under considerable pressure from employers to control their premiums. In the past two years, premiums have been increasing at a slower rate and in some instances premiums have actually decreased. Some of the premium savings have been achieved by increasing deductibles or coinsurance for subscribers; other savings are the result of continued pressures on payment and rates of use. Health maintenance organisations and other managed care firms are consolidating and using their larger share of the market to force providers to accept lower payments. They are also continuing their efforts to manage - that is, reduce - use. Ellwood, an important managed care pioneer, recently noted that health maintenance organi- sations are placing too much emphasis on cutting costs and not enough on quality. ${ }^{32}$

Management of use is the source of most managed care horror stories. For example, most managed care plans have reduced their allowable inpatient days for mothers with normal vaginal deliveries. The 24 hour stay has become the norm in some parts of the country. There has been some anecdotal evidence that mothers and babies have not been adequately prepared for discharge and that appropriate home care was not available. The anecdotes were numerous enough to prompt some states to pass legislation requiring all insurance plans to cover at least two days postpartum. ${ }^{33}$ This represents an interesting turn of events. Managed care firms have been accused of micromanaging patient care; now state legislators have started to micromanage the health plans.

Although there is considerable concern about managed care today, there are signs that the best managed care companies recognise that they cannot compete on the basis of costs alone; they must show that they offer value, a measure that encompasses cost and quality. In fact, some of the largest employers in the United States are demanding that managed care plans measure and report their performance with a variety of quality indicators. ${ }^{32}$ The employers are using these report cards to select plans to offer their employees.

The managed care experience in the United States seems to have added to the confusion about the relation between quality and cost or expenditure containment. Early experiences suggested that lower expenditures need not mean lower quality, but reducing slack is a one time correction. Consequently, recent experience is more ambiguous. Some current managed care practices may sacrifice quality in the interest of containment of expenditure; others may not. It is not surprising, therefore, that it is difficult to achieve a national consensus about health reform if the meanings of quality, costs, and cost containment, and the impact of managed care on all three, are not clear.

\section{Framework for the health reform debate}

The reform debates in the United States have focused primarily on two issues - expanding access to insurance coverage and containing expenditures. The access issue has received some attention, mostly at the state level. However, expenditure control of public financing (Medicare and Medicaid) is the primary item on the public agenda. Quality issues have been and still are secondary, if not totally ignored, in the public policy debates.

We argue that the healthcare debate, as framed, starts with the wrong issues, asks the wrong questions, and uses inadequately defined terms, often interchangeably. We further argue that the United States will not be able to contain expenditures, either public or private, until quality and the true cost of providing quality are more clearly understood and defined. Only then can the United States 
achieve a consensus about the level of expenditures the nation can afford or wants to spend to provide quality healthcare. Therefore, we propose the following framework to guide public discussion about reform in the future.

\section{QUALITY}

Quality should be the lead issue in the health reform debate, not an afterthought. Quality should be defined in terms of outcomes of care and the healthcare system's goal should be to finance improvements in the health of its citizens. Access to care is an important public policy issue. However, we do not think that access to or availability of the outputs of care are adequate measures of quality. A focus on outcomes will also require a long term perspective in planning for health system reform. Some outcomes cannot be measured in the short term. We think that a long term perspective will inevitably give higher priority to preventive services of proved effectiveness.

Quality should be the lead issue
in the health reform debate, not
an afterthought.

Of course, there is much yet to learn about how to produce quality, how to produce a healthy population. There is a need to know more about the effectiveness of various medical practices, including some preventive services, so that appropriate care from providers can be defined. There is a need to know more about how to help people change their health behaviours, so that the consumer's role in producing quality can be defined.

Managed care organisations in the United States are in a particularly good position to do some of this work. Unlike direct care providers, they have the potential to collect data on the whole continuum of care for the populations they insure; some of the best plans have started to do just that. A good managed care plan should, by definition, be one that commits resources to outcomes research and to educating the public about its findings. The work that is already in progress throughout the United States on medical effectiveness, outcomes research, and lifestyle change deserves the same public support and media coverage as the latest biomedical breakthroughs.

\section{cost}

The relation between quality and cost is a critical issue to understand. If there is agreement on what constitutes quality, the focus of public attention can be on the cost of quality. What should it cost to produce the desired outcomes? As we have already stated, many good examples show that quality and cost are not always a trade off - that is, lower costs do not inevitably lower quality of care. Yet there are circumstances in which controls on expenditure may sacrifice quality. The public's concerns are not completely unjustified.

However, the public is not alone in its confusion on this issue. Certainly many hospitals and physicians have bought into and reinforced our American fascination with technology and have advocated widespread diffusion of technology without asking questions about the impact on outcomes. And despite its enthusiasm for total quality management and continuous quality improvement, the healthcare industry is often resistant to rethinking the way it does business. The love of invention in terms of equipment and procedures contrasts with the system's resistance to changes in the process of care that might decrease costs and increase quality.

\section{The healthcare industry is often resistant to rethinking the way it does business.}

Once again, there is a lot yet to learn. There is not enough evidence about how much money, if any, could be saved with no diminution or even improvement in quality. There is much work to be done in terms of continuous quality improvement and process reengineering to determine the true cost of quality; a growing number of integrated delivery systems in the United States have started to do just that. A good integrated delivery system should, by definition, be one that commits resources to this kind of work and to public education about its findings.

\section{EXPENDITURES}

We think that if policy deliberations begin by defining quality and cost, it will be easier to set expenditure goals. If quality is defined in terms of outcomes, the cost to produce the desired outcomes is measured, and the impact of improved health is understood, then policy makers and the public can decide their willingness to pay for a given level of quality. If health expenditures grow faster than the resources to finance them (be those government revenues, corporate profits, or consumer incomes), then health care will inevitably crowd out expenditures for other goods and services. ${ }^{34}$ The public may conclude that is acceptable if those expenditures are, in fact, paying for better health. Or Americans may choose to limit health care's share of the economy in the interest of economic growth, which can affect health as well.

\section{Conclusion}

The outcome of the debate on the future of the United States healthcare system will be determined, in large part, by attaining better understandings of quality, costs, control of expenditure, and their relations with each other. The keys to meeting this challenge are clarity of definitions, solid research data, and education of the public. Horror stories, political positioning, and self interest will not advance the debate. It is also critical that participants in the debate move away from their historical position that quality declines when costs (expenditures) are reduced. They should accept the challenge of redefining desired outcomes and re-engineering and inte- 
grating delivery systems to enhance quality. They should adopt the perspective that cost, although an important factor in decisions made by employers, patients, and policy makers, does not necessarily equate with quality.

\section{Cost, although an important factor in decisions made by employers, patients, and policy makers, does not necessarily equate with quality.}

1 McManus SM, Thai KV. Health care financing: a comparative analysis. Public Budgeting and Financial Management 1995;7:279-314.

2 Schieber G, Poullier JP, Greenwald L. Health system performance in OECD countries. Health Aff 1992;11:10112 .

3 Reinhardt U. Providing access to health care and controlling costs: the universal dilemma. In: P Lee, C Estes, ed. The nation's health.Boston: Jones and Bartlett 1994:263-78.

4 Yankelovich D. The debate that wasn't: the public and the Clinton plan. Health Aff 1995;14:7-23.

5 Schoenbaum SC. Health care reform and its implications for quality of care. Med Care 1995;33:JS37-40.

6 Blendon RJ, Brodie $M$, Benson J. What happened to support for the Clinton plan? Health Aff 1995;14:7-23.

7 Blumenthal D. Health care reform-past and future. $\mathrm{N} \mathrm{Engl}$ Med 1995;332:465-8.

8 Mongon J. Anatomy and physiology of health reform's failure. Health Aff 1995;14:99-101.

9 Rosko MD, Carpenter CE. Hospital markups: responses to evironmental pressures in Pennsylvania. Hospital and Health Services Administration 1994;39:3-16.

10 Legorreta A, Silber JH, Costantino GN, Kobylinski RW, Zatz SL. Increased cholecystectomy rate after the
introduction of laparoscopic cholecystectomy. $\mathscr{f} A M A$ introduction of lap

11 Fries J, Koop CE, Beadle CE, Cooper PP, England MJ, Greaves RF, et al. Reducing health care costs by reducing the need and demand for medical services. $N$ Engl $f$ Med 1993;329:321-5.

12 Levit K, Cowan CA, Lazenby HC, McDonnell PA, Sensenig AL, Stiller J. National health spending trends, 1960-93. Health Aff 1994;13:14-31.

13 Mechanic D. America's health care system and its future: the view of a despairing optimist. Medical Care Review 1991;29:7-47.
14 Samuelson R. Health care: how we got into this mess. Newsweek 1993;122:30-5.

15 Hsiao W. Comparing health care systems: what nations can learn from one another. $f$ Health Polit, Policy, Law 1992;17:613-36.

16 Fuchs $\mathrm{V}$. The best health care system in the world? Health care around the world. New York: Newsweek, 1994:18-9.

17 Eddy D. Variations in physician practice: the role of uncertainty. Health Aff 1984;3:74-89.

18 Office of Technology Assessment. Identifying health technologies that work. Washington, DC: Government Printing Office, 1994:1.

19 Evans J. Total quality: gains in the business sector. fournal of Health Administration Education 1995;13 :3-14.

20 Deming WE. Out of the crisis. Cambridge, MA: Massachusetts Institute of Technology Center for Advanced Engineering Study, 1982

21 Nash D, Carpenter C. Role of clinical evaluation in academic medical centers: results of a national survey. Acad Med 1995;70:239-41.

22 Evidence-Based Medicine Working Group. A new approach to teaching the practice of medicine. $\mathcal{F} A M A 1992$ 268:2420-5.

23 Morris A. Paradigms in management. Pathophysiologic foundations of critical care medicine. Baltimore, MD: Williams and Wilkins, 1992:1-18.

24 Wennberg J. Improving the medical decision-making process. Health Aff 1988; 7:99-106.

25 Fleming C, Wasson JH, Albertsen PC, Barry MJ, Weanberg JE. A decision analysis of alternative treatment strategies for clinically localised prostate cancer. $\mathcal{F A M A} 1993$ 269:2650-8.

26 Larsen RA, Evans RS, Burke PJ, Pestonick SL, Gardner $\mathrm{RM}$, Classen DC. Improved perioperative antibiotic use and reduced surgical wound infections through use of computer decision analysis. Infect Control Hosp Epidemiol 1990.

27 McGlynn EA, Naylor CD, Anderson GM, Leape LL, Park $\mathrm{RE}$, Hilborne LH, et al. Comparison of the appropriateness of coronary artery bypass graft surgery between

28 Rosko MD, Chilingerian JA, Zinn JS, Aaronson WE. The effects of ownership, operating environment, and strategic choices on nursing home efficiency. Med Care 1995, 3:1001-21.

29 Berwick DM. Eleven worthy aims for clinical leadership of health system reform. $\mathcal{F A M A} 1994 ; 272: 797-802$.

30 Luft H. Health maintenance organizations. Dimensions of performance. New York: John Wiley 1988 .

31 Newhouse JP. An iconoclastic view of health cost containment. Health Aff 1993;12:155.

32 Noble HB. Quality is focus for health plans. New York: New York Times, July 3, 1995.

33 Burling S. Maternity stay gets a 2nd day. Philadelphia: Philadelphia Inquirer, October 1995.

34 Evans RG. Health care as a threat to health: defense, opulence, and the social environment. Daedalus. 1994; 123:21-42. 